\title{
Sodium formate induces autophagy and apoptosis via the JNK signaling pathway of photoreceptor cells
}

\author{
YING WANG ${ }^{1}$, SHAO-LIN XU ${ }^{1}$, WEN-JING XU ${ }^{1}$, HAI-YAN YANG ${ }^{1}$, PING HU $^{1}$ and YU-XIN LI ${ }^{2}$ \\ ${ }^{1}$ Department of Ophthalmology, The Second Hospital of Jilin University, Changchun, Jilin 130041; \\ ${ }^{2}$ Department of Biology, National Engineering Laboratory for Druggable Gene and Protein Screening, \\ Northeast Normal University, Changchun, Jilin 130024, P.R. China
}

Received March 25, 2015; Accepted October 29, 2015

DOI: $10.3892 / \mathrm{mmr} .2015 .4675$

\begin{abstract}
Incidents associated with methanol intoxication resulting from the consumption of fake wine occur not infrequently worldwide. Certain individuals are made blind due to methanol poisoning. The present study aimed to investigate the effects of sodium formate exposure on photoreceptor cells (661W cells). The $661 \mathrm{~W}$ cells were exposed to sodium formate for $6-24 \mathrm{~h}$ and cell viability was determined using a 3-(4,5-dimethylthiazol-2-yl)-2,5-diphenyl-2H-tetrazolium bromide (MTT) assay. Subsequently, the $661 \mathrm{~W}$ cells were exposed to 15 or $30 \mathrm{mM}$ sodium formate for $24 \mathrm{~h}$. The level of apoptosis was determined using Hoechst 33342/propidium iodide staining, visualizing the cells under a fluorescence microscope, and annexin V-fluorescein isothiocyanate staining, using flow cytometric analysis. Intracellular reactive oxygen species (ROS) were measured using 2',7'-dichlorofluorescein diacetate (DCFH-DA) staining, followed by flow cytometric analysis. Autophagy of the $661 \mathrm{~W}$ cells was measured by monodansylcadaverine staining. The activation of phosphorylated c-Jun N-terminal kinase (p-JNK), B-cell lymphoma (Bcl-2), Bcl-2-associated X protein, cleaved caspase-3, cleaved caspase- 9 and microtubule-associated protein $1 \mathrm{~A} / 1 \mathrm{~B}$-light chain 3 (LC3) was assessed by western blotting. The effects of Z-VAD-fmk (a pan-caspase inhibitor) and SP600125 (a JNK inhibitor) on the viability of the sodium formate-induced $661 \mathrm{~W}$ cells were determined using an MTT assay. Sodium formate treatment induced a decrease in the viability of the $661 \mathrm{~W}$ cells in a time- and a dose-dependent manner. In addition, sodium formate at concentrations of 15 or $30 \mathrm{mM}$ markedly increased the level of apoptosis and the ROS levels, as measured by DCFH-DA staining of the $661 \mathrm{~W}$ cells. Additionally, $661 \mathrm{~W}$ cells exposed to sodium formate for $24 \mathrm{~h}$ exhibited increased levels of p-JNK, Bax,
\end{abstract}

Correspondence to: Dr Shao-Lin Xu, Department of Ophthalmology, The Second Hospital of Jilin University, 4026 Yatai Street, Changchun, Jilin 130041, P.R. China

E-mail: wangying9201@163.com

Key words: sodium formate, autophagy, apoptosis, $661 \mathrm{~W}$ cells cleaved caspase-3, cleaved caspase-9 and LC3II (the phosphatidylethanolamine-modified form of LC3), although the level of Bcl-2 was decreased. Furthermore, cell cytotoxicity and autophagy were induced upon treatment with sodium formate. Z-VAD-fmk and SP600125 were able to effectively circumvent the effects of sodium formate on cell viability. These results suggested that the cytotoxicity induced by sodium formate induces the activation of the JNK signaling pathway, leading to caspase-dependent apoptosis. Increased levels of autophagy were also observed during the process of $661 \mathrm{~W}$ cell damage induced by sodium formate.

\section{Introduction}

Methanol intoxication resulting from the consumption of fake wine has led to numerous incidents of disability, blindness and mortality as a consequence of selective neurotoxic actions (1). Methanol is metabolized primarily in the liver by sequential oxidative steps to form formic acid, formaldehyde and carbon dioxide $(2,3)$. Previous studies hypothesized that the retinal pathophysiology of methanol intoxication is a consequence of formate-induced mitochondrial dysfunction (4). Formate disrupts mitochondrial electron transport and energy production by inhibiting cytochrome oxidase activity and the terminal electron acceptor of the electron transport chain (4). Cell death resulting from cytochrome oxidase inhibition by formate is considered to result partly from the depletion of ATP, which reduces energy levels and leads to the disruption of cell functions (5). Furthermore, concentrations of formate in the retina and vitreous humor closely correspond to the concentration of formate in the blood $(6,7)$.

It was previously reported that formate may inhibit cytochrome oxidase activity in the concentration range of 5-30 mM in vitro and in vivo (8). Similar formate levels have been measured in the blood, vitreous humor and cerebrospinal fluid of methanol-poisoned humans and monkeys $(9,10)$. However, since tissues differ in their sensitivity to the toxic effects of methanol poisoning, and the retina is highly susceptible to depletion of retinal ATP due to its constant exposure to irradiation and a high metabolic activity, it remains to be elucidated whether patterns of cell death in the retina may be attributable to induction by methanol poisoning. 
The present study aimed to investigate the effects of sodium formate on $661 \mathrm{~W}$ cells in order to understand the molecular events of cell death caused by methanol poisoning. An improved understanding of this mechanism is required in order to identify more effective treatments for patients with methanol intoxication.

\section{Materials and methods}

Ethical approval. All human and animal experiments performed in the present study were approved by the Human and Animal Research Ethics Committees of The Second Hospital of Jilin University, (Changchun, China).

Antibodies and reagents. Polyclonal rabbit anti-mouse antibodies raised against $\mathrm{Bax}$ and $\mathrm{Bcl}-2$ were obtained from Santa Cruz Biotechnology, Inc. (Dallas, TX, USA; cat. nos. sc-6236 and sc-492). Antibodies against cleaved caspase-9 (cat. no. 7237), cleaved caspase-3 (cat. no. 9579), c-Jun N-terminal kinase (JNK; cat. no. 9251), phosphorylated (p)-JNK (cat. no. 9252) and microtubule-associated protein 1A/1B-light chain 3 (LC3; cat. no. 2775) were purchased from Cell Signaling Technology, Inc. (Beverly, MA, USA). A mouse monoclonal antibody against glyceraldehyde-3-phosphate dehydrogenase was purchased from Kangchen Bio-Tech Co., Ltd. (Shanghai, China; cat. no. kc-564). All primary antibodies were diluted 1:1,000. The secondary antibodies (goat anti-rabbit; cat. no. 31210; 1:5,000) were obtained from Thermo Fisher Scientific, Inc. (Waltham, MA, USA). An enhanced chemiluminescence (ECL)-Plus kit was purchased from Beyotime Institute of Biotechnology (Nantong, China). An annexin V-FLUOS Staining kit was purchased from Roche Diagnostics (Mannheim, Germany). Sodium formate was purchased from Sinopharm Chemical Reagent Co., Ltd. (Shanghai, China). Hoechst 33342 stain, propidium iodide (PI), 3-(4,5-dimethylthiazol-2-yl)-2,5-diphenyl-2H-tetrazolium bromide (MTT), monodansylcadaverine (MDC), SP600125, Z-VAD-fmk and 2',7'-dichlorofluorescein diacetate (DCFH-DA) were obtained from Sigma-Aldrich (St. Louis, MO, USA).

Cell culture. The $661 \mathrm{~W}$ cells were obtained from American Tissue Culture Collection (Manassas, VA, USA) and were maintained in Dulbecco's modified Eagle's medium, supplemented with $10 \%$ fetal bovine serum (Gibco; Thermo Fisher Scientific, Inc.), $100 \mathrm{U} / \mathrm{ml}$ penicillin and $100 \mathrm{~g} / \mathrm{ml}$ streptomycin (Gibco; Thermo Fisher Scientific, Inc.). The cells were grown in a humidified incubator with $95 \%$ air and $5 \% \mathrm{CO}_{2}$ at $37^{\circ} \mathrm{C}$. Subsequently, the cells were passaged until they reached $80 \%$ confluence.

Cell viability assays. The $661 \mathrm{~W}$ cells were plated at a density of $5 \times 10^{3}$ cells/well in 96-well plates. Following incubation for $24 \mathrm{~h}$, culture medium containing various final formate concentrations $(0,15,30,60$ or $120 \mathrm{mM})$ was added to each well. Paired control cultures were prepared with medium containing comparable levels of sodium chloride (sodium control). The parallel cell cultures were incubated for 6, 12 or $24 \mathrm{~h}$. Subsequently, 661W cells were pretreated with a pan-caspase inhibitor (Z-VAD-fmk) and a JNK inhibitor
(SP600125) for $0.5 \mathrm{~h}$ prior to treatment with $30 \mathrm{mM}$ sodium formate for $24 \mathrm{~h}$. MTT $(20 \mu \mathrm{l})$ was added to each well and the samples were incubated for an additional $4 \mathrm{~h}$ followed by the addition of $100 \mu \mathrm{l}$ dimethylsulfoxide to each well. The absorbance of blue formazan at $570 \mathrm{~nm}$ was measured using a microplate reader (Model 680; Bio-Tek Instruments, Inc., Winooski, VT, USA).

Hoechst 33342 and PI staining. The level of apoptosis of the $661 \mathrm{~W}$ cells was determined using double staining with Hoechst 33342 and PI. The cells were stained with $10 \mu \mathrm{g} / \mathrm{ml}$ Hoechst 33342 and $10 \mu \mathrm{g} / \mathrm{ml}$ PI for $30 \mathrm{~min}$ at $37^{\circ} \mathrm{C}$. Following two successive washes with phosphate-buffered saline (PBS), images of the cells were captured with a digital camera attached to a fluorescence microscope (IX70; Olympus Corporation, Tokyo, Japan).

Annexin V-fluorescein isothiocyanate (FITC) assay. The percentage of cells actively undergoing apoptosis was determined using flow cytometric analysis with the annexin V-FITC Apoptosis Detection kit (BD Biosciences, San Jose, CA, USA), according to the manufacturer's protocol. Briefly, the cells were harvested and resuspended in binding buffer $\left(10^{6}\right.$ cells $\left./ \mathrm{ml}\right)$. The cells at a density of $10^{3}$ cells/well were mixed with $5 \mu \mathrm{l}$ annexin V-FITC and $5 \mu \mathrm{l}$ PI. Following incubation of the cells at room temperature for $15 \mathrm{~min}$ in the dark, the flow cytometric analysis was performed using the FACSCalibur ${ }^{\mathrm{TM}}$ system (BD Biosciences, Franklin Lakes, NJ, USA).

ROS measurement. Intracellular ROS production was assessed using a fluorescent probe, DCFH-DA, using flow cytometric analysis, as previously described (10). Detection of ROS was based on the fact that intracellular ROS are able to oxidize DCFH, yielding the fluorescent product, 2',7'-dichlorofluorescein (DCF). Following an incubation of the cells with 0,15 , or $30 \mathrm{mM}$ formate for $24 \mathrm{~h}$, the supernatant was removed, and the cells were washed with PBS three times. The cells were subsequently harvested and suspended in PBS. DCFH-DA (10 $\mu \mathrm{M}$ final concentration) was added and the mixture was incubated at $37^{\circ} \mathrm{C}$ for $15 \mathrm{~min}$. Finally, ROS generation was measured, according to the fluorescence intensity (FL-1; $530 \mathrm{~nm}$ ) of $10^{4}$ cells using a flow cytometer (FACSCalibur; BD Biosciences).

MDC staining. MDC (Sigma-Aldrich) was used to visualize autophagic vacuoles. The $661 \mathrm{~W}$ cells were plated into 6-well plates and treated with two different concentrations of formate (15 or $30 \mathrm{mM}$ ) for $6 \mathrm{~h}$. Following treatment, the cells were incubated with $0.1 \mathrm{mM}$ MDC for $30 \mathrm{~min}$. Fluorescent images were captured under a fluorescence microscope (Olympus).

Western blotting. The proteins $(2.6 \mu \mathrm{g} / \mu \mathrm{l})$ were separated by sodium dodecyl sulfate-polyacrylamide gel electrophoresis (SDS-PAGE), and western blotting was subsequently performed, as previously described (11). Briefly, the cells were harvested, resuspended in cell lysis buffer (Beyotime Institute of Biotechnology) and incubated on ice for $30 \mathrm{~min}$. The cell lysates were centrifuged at $12,000 \mathrm{xg}$ for $10 \mathrm{~min}$ at $4^{\circ} \mathrm{C}$. The supernatants were mixed with one-quarter volumes of $4 \mathrm{X}$ SDS 


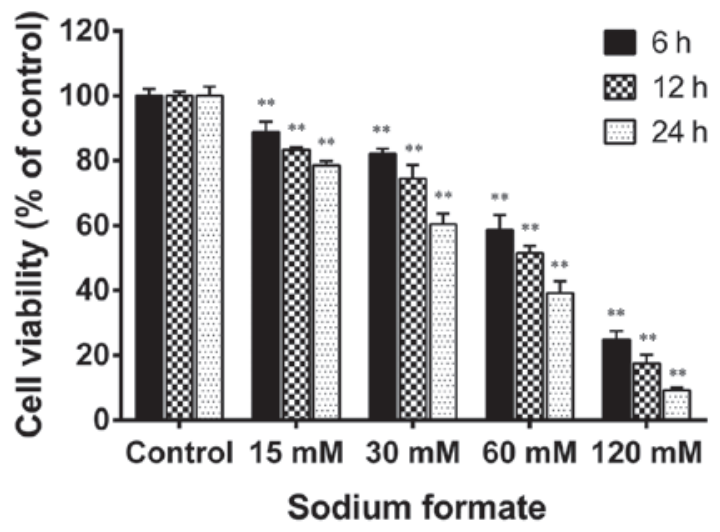

Figure 1 . Sodium formate reduced the viability of $661 \mathrm{~W}$ cells. The $661 \mathrm{~W}$ cells were treated with $0,15,30,60$ or $120 \mathrm{mM}$ sodium formate. Following treatment for 6-24 h, $20 \mu 1$ (3-(4,5-Dimethylthiazol-2-yl)-2,5-Diphenyltetrazol ium Bromide was added to each well, followed by an incubation for an additional $4 \mathrm{~h}$. The data revealed the relative proportion of viable cells $(\%)$ in the sodium formate-treated and control groups. The results are expressed as the mean \pm standard deviation of three independent experiments $\left({ }^{*} \mathrm{P}<0.05\right.$; ${ }^{* *} \mathrm{P}<0.01$, sodium formate-treated vs. control).

sample buffer and boiled for $10 \mathrm{~min}$. The proteins were subsequently separated by SDS-PAGE in a $10-15 \%$ gel. Following electrophoresis, the proteins were transferred onto polyvinylidene fluoride membranes and blocked with 5\% non-fat milk powder in Tris-buffered saline (Thermo Fisher Scientific, Inc.) with Tween-20 (TBST; Beyotime Institute of Biotechnology) for $1 \mathrm{~h}$ at room temperature. The membrane was subsequently incubated with a diluted primary antibody in blocking buffer overnight at $4^{\circ} \mathrm{C}$. The membrane was washed three times with TBST and incubated with a horseradish peroxidase-conjugated secondary antibody (Beyotime Institute of Biotechnology) for $30 \mathrm{~min}$ at room temperature. Following extensive washing, the proteins were visualized using an ECL-Plus kit and the blots were exposed to Kodak radiographic film (Kodak. Corp., Rochester, NY, USA).

Statistical analysis. The data were obtained from $>3$ independent experiments. Statistically significant differences between the groups were assessed by one-way analysis of variance, followed by the Bonferroni post-hoc test, using SPSS 13.0 software for statistical analysis (SPSS Inc., Chicago, IL, USA). The data are expressed as the standard deviation, unless otherwise stated. $\mathrm{P}<0.05$ was considered to indicate a statistically significant difference.

\section{Results}

Effects of sodium formate on the viability of $661 \mathrm{~W}$ cells. The cytotoxicity of sodium formate in $661 \mathrm{~W}$ cells was examined using an MTT assay. As shown in Fig. 1, sodium formate treatment reduced the cell viability in a time- and a dose-dependent manner. The viability of the $661 \mathrm{~W}$ cells treated with $120 \mathrm{mM}$ sodium formate for $24 \mathrm{~h}$ was decreased by a greater extent compared with the other concentrations tested $(15,30$, and $60 \mathrm{mM})$. The viability of the $661 \mathrm{~W}$ cells treated with 15 or $30 \mathrm{mM}$ sodium formate for $24 \mathrm{~h}$ was 78.5 and $60.4 \%$, respectively, compared with the control group. The $661 \mathrm{~W}$ cells were also treated with $5 \mathrm{mM}$ sodium

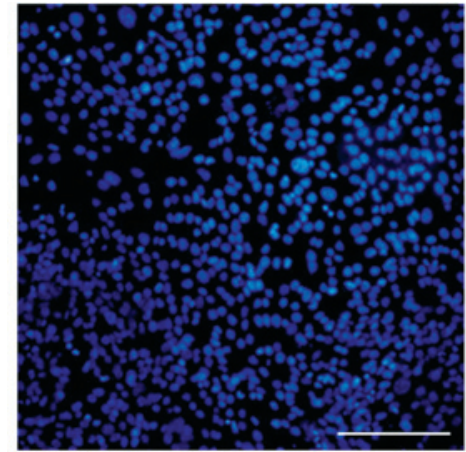

Control

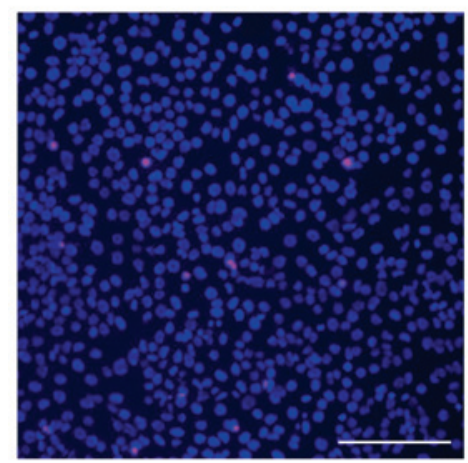

$15 \mathrm{mM}$

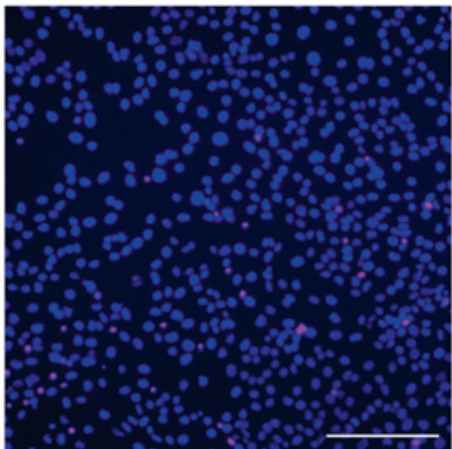

$30 \mathrm{mM}$

Figure 2. Hoechst 33342 and propidium iodide double staining in 661W cells Sodium formate treatment increased cell apoptosis in the $661 \mathrm{~W}$ cells. The $661 \mathrm{~W}$ cells were exposed to 0 (control), 15 or $30 \mathrm{mM}$ sodium formate for $24 \mathrm{~h}$. Representative images are shown (scale bar $=100 \mu \mathrm{m}$ ).

formate (data not shown), and the results revealed no clear differences compared with the control cultures. Therefore, the concentrations of sodium formate used in the subsequent experiments were 15 and $30 \mathrm{mM}$. No discrimination was made between the paired control cultures in the viability assays and those in further experiments. Therefore, the paired control results (15 $\mathrm{mM}$ sodium chloride) were used in the following experiments. These results suggested that treatment of the $661 \mathrm{~W}$ cells with sodium formate led to a marked decline in their viability.

Sodium formate induces apoptosis in $661 \mathrm{~W}$ cells. The cytotoxicity of sodium formate towards the $661 \mathrm{~W}$ cells was further assessed using Hoechst 33342 and PI double staining. As shown in Fig. 2, exposure to $30 \mathrm{mM}$ sodium formate for $24 \mathrm{~h}$ resulted in a marked loss of Hoechst-positive 
A

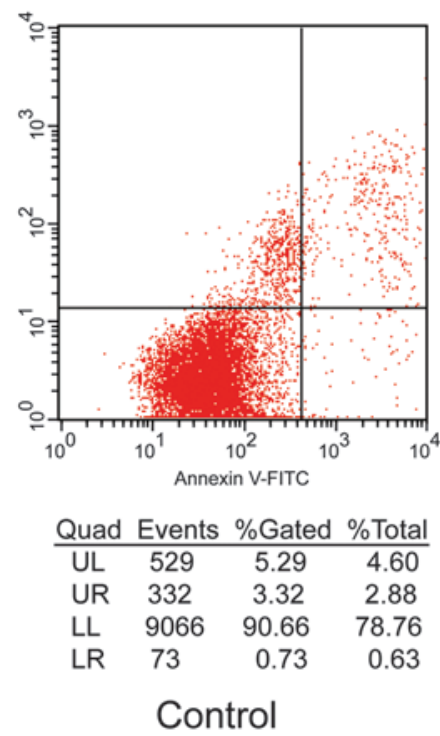

B

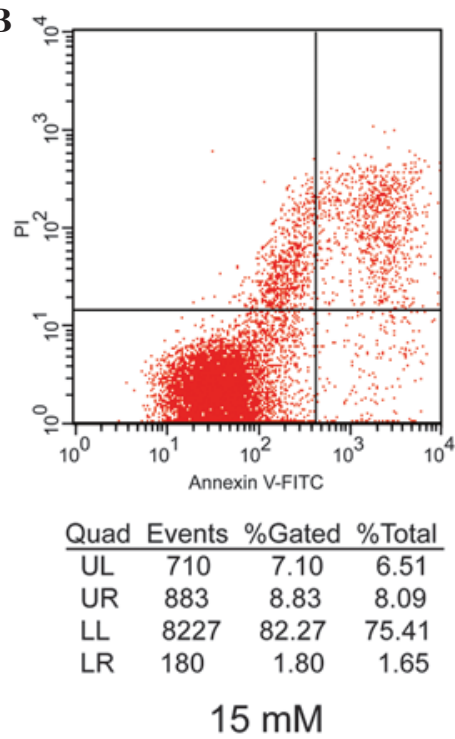

C

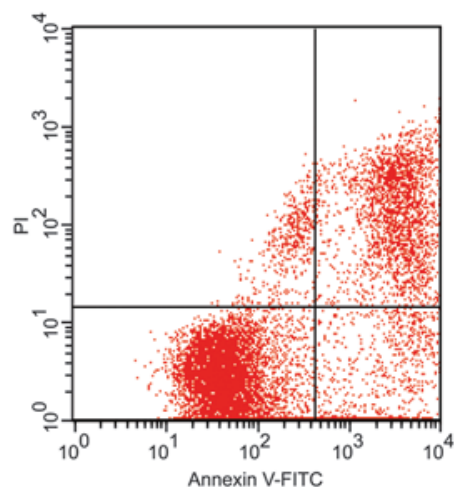

Quad Events \%Gated \%Total

$\begin{array}{llll}\text { UL } & 416 & 4.16 & 3.42\end{array}$

UR $2244 \quad 22.44 \quad 18.43$

LL $\quad 6573 \quad 65.73 \quad 53.98$

$\begin{array}{llrr}\text { LR } & 767 & 7.67 & 6.30\end{array}$

$30 \mathrm{mM}$

Figure 3. Effects of sodium formate on the apoptosis of 661W cells, as determined by an annexin V-FITC assay using flow cytometric analysis. The 661W cells were exposed to (A) 0 (control), (B) 15 or (C) $30 \mathrm{mM}$ sodium formate for $24 \mathrm{~h}$. The cultures were stained with annexin V-FITC and PI. FITC, fluorescein isothocyanate; PI, propidium iodide; Quad, quadrant; UL, upper left; UR, upper right; LL, lower left; LR, lower right.

cells and numerous PI-positive cells, indicating that apoptosis of the $661 \mathrm{~W}$ cells was induced upon treatment with 15 or $30 \mathrm{mM}$ sodium formate.

The apoptotic rates of the $661 \mathrm{~W}$ cells were further assessed by flow cytometric analysis using the annexin V-FITC Apoptosis Detection kit, which readily distinguishes early apoptotic events from late apoptosis/necrosis. In the premature apoptotic cells, the membrane phospholipid, phosphatidylserine (PS), is translocated from the inner to the outer leaflet of the plasma membrane, and annexin $\mathrm{V}$ is a protein that has a high affinity for PS. PI is used as a flow cytometric viability probe for DNA content and can be used to differentiate viable from non-viable cells. Following exposure to the two different doses (15 and $30 \mathrm{mM}$ ) of sodium formate for $24 \mathrm{~h}$, markedly different percentages of early apoptotic and late apoptotic/necrotic $661 \mathrm{~W}$ cells compared with control cells (0 $\mu \mathrm{M}$ sodium formate) were identified, which increased from 2.88 to $18.43 \%$ and from 0.63 to $6.3 \%$, respectively (Fig. 3). The results indicated that the level of apoptosis of the $661 \mathrm{~W}$ cells treated with 15 or $30 \mathrm{mM}$ sodium formate was markedly increased.

Sodium formate causes an increase in the intracellular ROS levels. DCFH-DA staining was used to detect intracellular ROS generation. DCFH-DA readily diffuses through the cell membrane and is deacetylated by esterases to non-fluorescent DCFH. Furthermore, DCFH is rapidly oxidized to its highly fluorescent product, DCF, in the presence of ROS. Therefore, the DCF fluorescence intensity is proportional to the quantity of intracellular ROS present. As shown in Fig. 4A, a shift to the right was observed in the fluorescence intensity signal for the $661 \mathrm{~W}$ cells treated with 15 and $30 \mathrm{mM}$ sodium formate. The level of ROS increased markedly following exposure of the cells to 15 or $30 \mathrm{mM}$ sodium formate for $24 \mathrm{~h}$ (Fig. 4B). These results suggested that increased levels of ROS may be involved in sodium formate-induced cytotoxicity in $661 \mathrm{~W}$ cells.
$J N K$ is activated in $661 \mathrm{~W}$ cells following exposure to sodium formate. The protein expression of JNK and p-JNK in $661 \mathrm{~W}$ cells treated with sodium formate was subsequently examined. As shown in Fig. 5, the protein expression level of p-JNK increased in the $661 \mathrm{~W}$ cells upon sodium formate treatment, whereas no significant changes in the protein expression level of JNK were identified following treatment of the cells with either concentration of sodium formate (15 or $30 \mathrm{mM}$ ). These results suggested that the JNK signaling pathway was activated when $661 \mathrm{~W}$ cells were treated with sodium formate.

Sodium formate affects the protein expression levels of Bax and Bcl-2 in $661 \mathrm{~W}$ cells. Considering the role of the Bcl-2 family proteins in mitochondria-dependent apoptosis, the effects of sodium formate on the expression of the antiapoptotic protein, $\mathrm{Bcl}-2$, and the pro-apoptotic protein, Bax, were subsequently examined. As shown in Fig. 6, Bcl-2 levels were markedly decreased, and Bax levels were increased, in 661W cells treated with 15 or $30 \mathrm{mM}$ sodium formate, suggesting that the increase in the ratio of $\mathrm{Bax}$ to $\mathrm{Bcl}-2$ protein may be involved in mitochondria-dependent apoptosis following exposure to sodium formate.

Sodium formate triggers caspase-dependent apoptosis in $661 \mathrm{~W}$ cells. Apoptosis is triggered by two types of apoptotic caspases, namely initiator caspases (e.g. caspases-2, -8, -9 and -10) and effector caspases (e.g. caspases-3, -6 and -7). Initiator caspases cleave and activate inactive proforms of effector caspases, and activated effector caspases cleave other protein substrates to trigger the apoptotic process (12). In the present study, western blotting indicated that the level of cleaved caspase-3 increased when cells were treated with sodium formate (Fig. 7). Subsequently, the activity of initiator caspases was investigated. As shown in Fig. 7, treatment with sodium formate clearly increased the protein expression of cleaved caspase-9. These data suggested that sodium formate 
A

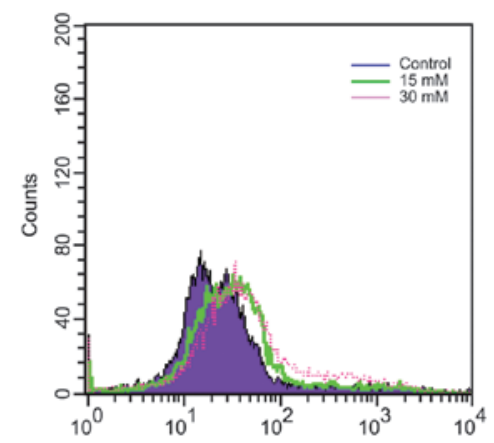

B

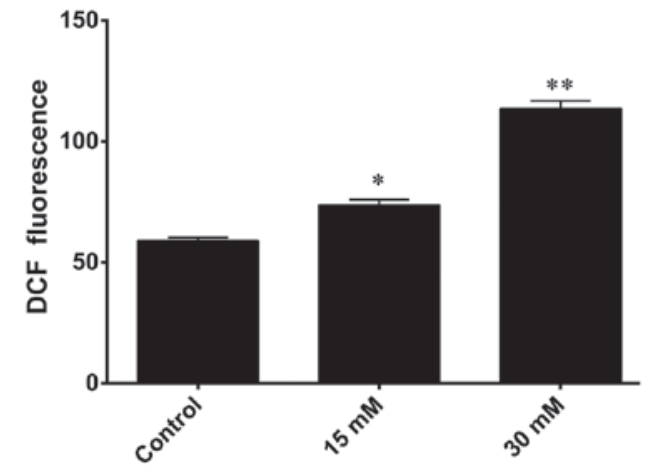

Figure 4. Sodium formate increased the basal levels of reactive oxygen species in $661 \mathrm{~W}$ cells. The $661 \mathrm{~W}$ cells treated with sodium formate $(15$ or $30 \mathrm{mM})$ were compared with the negative control by flow cytometric analysis using the fluorescent probe, DCF. (A) A shift to the right in the fluorescence intensity signal was observed for the $661 \mathrm{~W}$ cells treated with formate. (B) The fluorescence intensity of DCF was measured in the $661 \mathrm{~W}$ cells treated with $(15$ or $30 \mathrm{mM})$ or without sodium formate. $\left(\mathrm{P}<0.05 ;{ }^{* * *} \mathrm{P}<0.01\right.$, sodium formate-treated cells, vs. the control). DCF, dichlorofluorescein.

may induce apoptosis in $661 \mathrm{~W}$ cells, at least partly, via a caspase-dependent pathway.

Sodium formate exposure induces autophagy in $661 \mathrm{~W}$ cells. MDC is a specific marker for autophagic vacuoles. As shown in Fig. 8, the sodium formate-treated cells exhibited a greater fluorescence intensity and a greater number of MDC-labeled particles in the $661 \mathrm{~W}$ cells compared with the control, indicating that sodium formate increased the recruitment of MDC to autophagosomes in the cell cytoplasm.

LC3II levels increase in $661 W$ cells treated with sodium formate. LC3-I is a cytosolic protein whose lipidated form, LC3II (a phosphatidylethanolamine-modified form of LC3), is stably associated with the autophagosomal membrane, and is therefore considered an autophagy-specific marker. To determine whether sodium formate induces autophagy in $661 \mathrm{~W}$ cells, the expression level of LC3 was investigated by western blotting. Compared with the control, the levels of LC3-II were markedly increased in the $661 \mathrm{~W}$ cells treated with 15 or $30 \mathrm{mM}$ sodium formate (Fig. 9). No significant changes in the level of LC3-I was observed during the course of the experiment. These results suggested that autophagy may be involved in sodium formate-induced cytotoxicity in $661 \mathrm{~W}$ cells.

Effects of Z-VAD-fmk and SP600125 on cell viability in sodium formate-induced $661 \mathrm{~W}$ cell death. To assess the

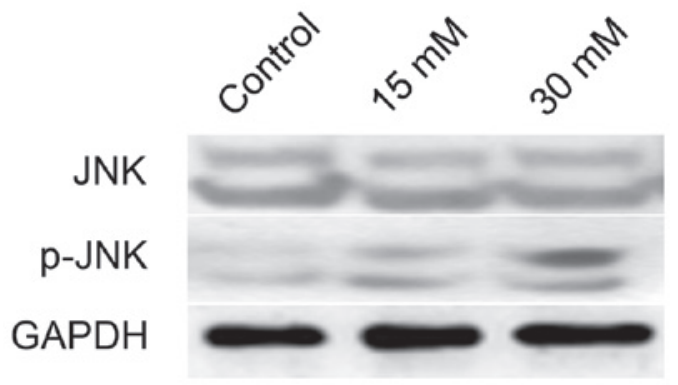

Figure $5.661 \mathrm{~W}$ cells were treated with 15 or $30 \mathrm{mM}$ sodium formate for $24 \mathrm{~h}$ The cell lysates were prepared and subjected to sodium dodecyl sulfate-polyacrylamide electrophoresis. The protein expression levels of JNK and p-JNK were determined by western blotting. GAPDH was used as an internal control to normalize the quantity of proteins applied to each lane. p-, phosphorylated; JNK, c-Jun N-terminal kinase; GADPH, glyceraldehyde-3-phosphate dehydrogenase.

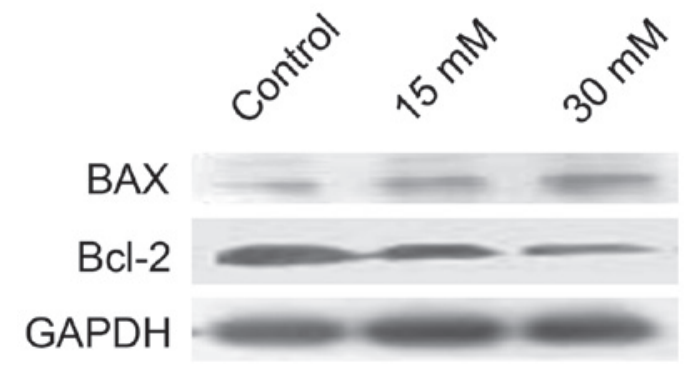

Figure 6. $661 \mathrm{~W}$ cells were treated with 15 or $30 \mathrm{mM}$ sodium formate for $24 \mathrm{~h}$. The cell lysates were prepared and subjected to sodium dodecyl sulfate-polyacrylamide electrophoresis. The protein expression levels of Bcl-2 and Bax were determined by western blotting. GAPDH was used as an internal control to normalize the amount of proteins applied in each lane. Bcl-2, B-cell lymphoma 2; Bax, Bcl-2-associated X protein; GADPH, glyceraldehyde-3-phosphate dehydrogenase.

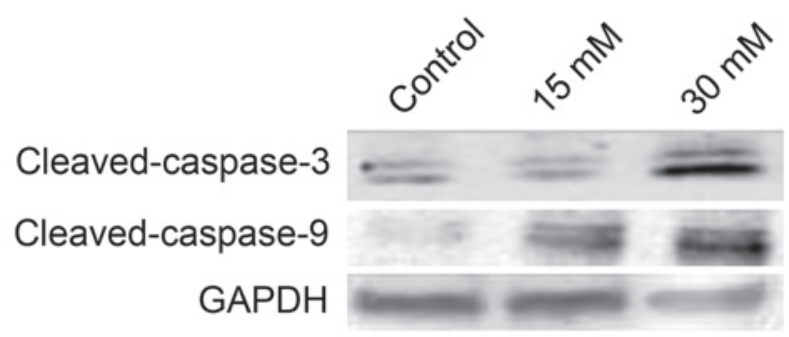

Figure 7. $661 \mathrm{~W}$ cells were treated with 15 or $30 \mathrm{mM}$ sodium formate for $24 \mathrm{~h}$. The cell lysates were prepared and subjected to sodium dodecyl sulfate-polyacrylamide electrophoresis. The protein expression levels of cleaved caspase- 3 and cleaved caspase- 9 were determined by western blotting with specific antibodies. GAPDH was used as an internal control to normalize the amount of proteins applied in each lane. GADPH, glyceraldehyde-3-phosphate dehydrogenase.

role of caspases in the cell death process induced by sodium formate, $661 \mathrm{~W}$ cells were pretreated with a pan-caspase inhibitor, Z-VAD-fmk, for $0.5 \mathrm{~h}$ prior to treatment with $30 \mathrm{mM}$ sodium formate for $24 \mathrm{~h}$. As shown in Fig. 10, Z-VAD-fmk at a concentration of $20 \mu \mathrm{M}$ effectively circumvented the effects of sodium formate on cell viability, resulting in only $19 \%$ growth inhibition, a value significantly lower compared with that observed in the untreated cells ( $40 \%$ inhibition; $\mathrm{P}<0.01$ ). 


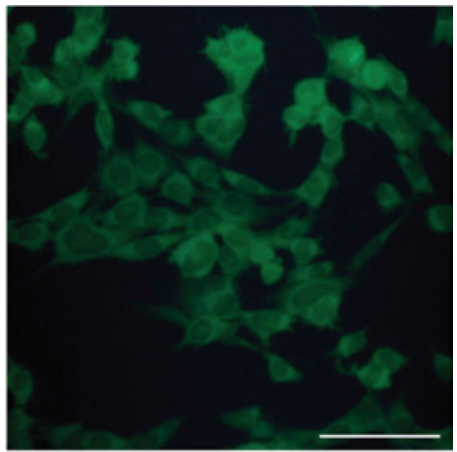

Control

B

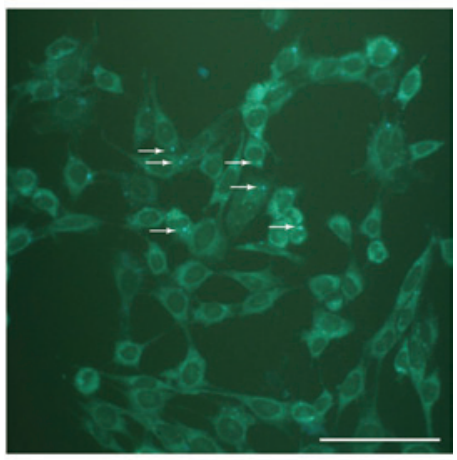

$15 \mathrm{mM}$

C

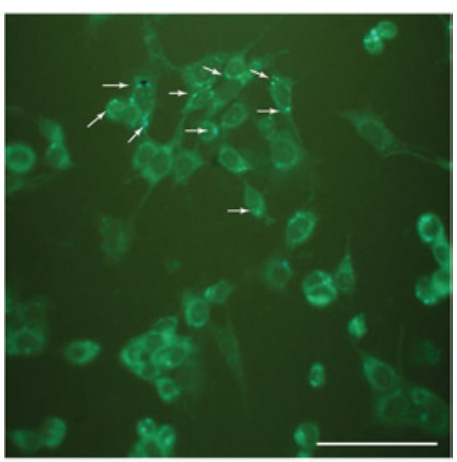

$30 \mathrm{mM}$

Figure 8. Sodium formate exposure induces the formation of MDC-positive autophagosomes in $661 \mathrm{~W}$ cells. The $661 \mathrm{~W}$ cells were exposed to (A) 0 (control), (B) 15 or (C) $30 \mathrm{mM}$ sodium formate. Autophagic vacuoles were labeled with $0.05 \mathrm{mM}$ MDC in phosphate-buffered saline at $37^{\circ} \mathrm{C}$ for $10 \mathrm{~min}$. The fluorescence density and the MDC-labeled particles in the $661 \mathrm{~W}$ cells were greater in the group subjected to sodium formate treatment for $6 \mathrm{~h}$ compared with the control group. MDC-labeled vesicles are indicated by arrows (Scale bar=50 $\mu \mathrm{m})$. MDC, monodansylcadaverine.

SP600125, at a concentration of $10 \mu \mathrm{M}$, clearly circumvented the effects of sodium formate on cell viability, resulting in only $20 \%$ growth inhibition, significantly lower compared with that observed in the untreated cells $(40 \%$ inhibition; $\mathrm{P}<0.01)$.

\section{Discussion}

Exposure to methanol is a major cause of acute alcohol intoxication. Patients with acute methanol intoxication experience acute neurological, visual and gastrointestinal symptoms. Visual disturbances generally range from mild photophobia and misty or blurred vision to markedly reduced visual acuity

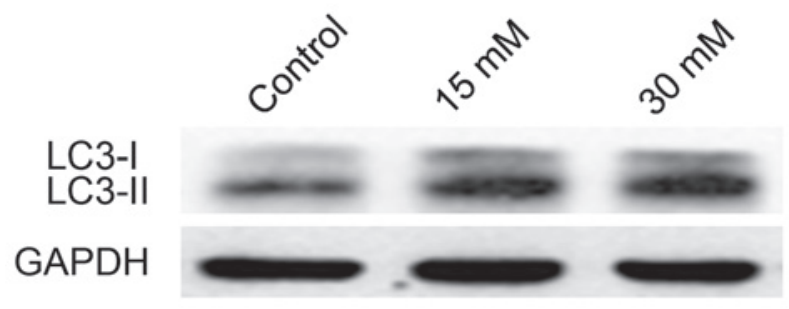

Figure 9. Cell lysates were analyzed by western blotting with anti-LC3 and GAPDH antibodies. GAPDH was used as an internal control to normalize the quantity of proteins applied in each lane. The protein expression of LC3-II increased in the $661 \mathrm{~W}$ cells treated with 15 or $30 \mathrm{mM}$ sodium formate. GADPH, glyceraldehyde-3-phosphate dehydrogenase; LC3, microtubule-associated protein 1A/1B-light chain 3.

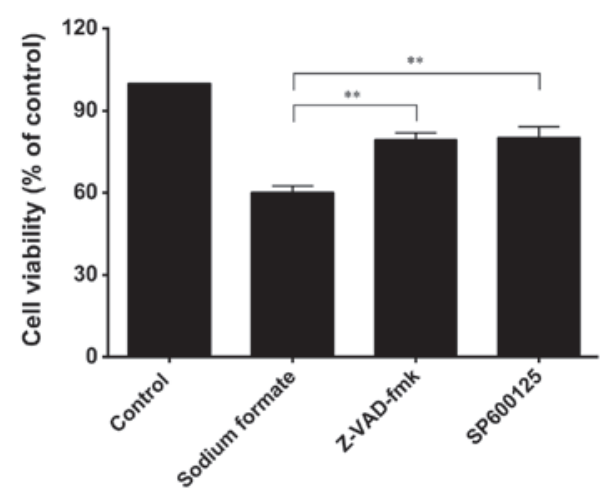

Figure 10. Effects of a pan-caspase inhibitor (Z-VAD-fmk) and c-Jun $\mathrm{N}$-terminal kinase inhibitor (SP600125) on the survival of $661 \mathrm{~W}$ cells treated with $30 \mathrm{mM}$ sodium formate, as determined using a (3-(4,5-Dimethylthiazol-2-yl)-2,5-Diphenyltetrazolium Bromide assay. The $661 \mathrm{~W}$ cells were cultured in $30 \mathrm{mM}$ sodium formate for $24 \mathrm{~h}$ in the presence or absence of the inhibitors. The data show the relative proportions of viable cells (\%). The results are expressed as the mean \pm standard deviation of three independent experiments $\left({ }^{*} \mathrm{P}<0.05 ;{ }^{* *} \mathrm{P}<0.01\right.$, sodium formate-treated cells, vs. the control).

and complete blindness. Despite the availability of efficient treatments, methanol poisoning results in high rates of morbidity and mortality $(1,13)$.

It was reported that retinal ATP synthase decreases following methanol intoxication. For example, proteomic analysis of the rat retina revealed that sodium formate induces a marked decrease in the levels of ATP in photoreceptor cells $(7,14)$. A marked decline in the viability of $661 \mathrm{~W}$ cells following exposure to sodium formate was also observed in the present study. It is well known that the dysregulation of electron transport through the mitochondrial respiratory chain, or impairments in the function of antioxidant enzymes, may result in the accumulation of ROS (15). Furthermore, ROS are associated with high levels of biological activity and function as secondary messengers in the JNK signaling pathway. As a member of the mitogen-activated protein kinase family, JNK is involved in the signal transduction of a variety of cellular pathways, including those for apoptosis, inflammation and carcinogenesis $(16,17)$. In the present study, the JNK signaling pathway was activated and the level of ROS increased when the $661 \mathrm{~W}$ cells were treated with sodium formate. ROS are potent activators of $\mathrm{JNK}$ via the process of oxidative inactivation of endogenous JNK inhibitors, including JNK 
phosphatases and glutathione S-transferase (18). Activation of the JNK pathway induces ROS accumulation, which may in turn activate JNK in a positive feedback manner. This activation may have contributed towards $661 \mathrm{~W}$ cell apoptosis following sodium formate treatment in the present study. Activation of the JNK signaling pathway triggers the apoptotic signaling pathway, including the intrinsic pathway (also termed the mitochondrial pathway) and the extrinsic pathway (also termed the death receptor pathway) (19). SP600125 is a specific JNK inhibitor in common usage. It was demonstrated to reverse neuronal cell death in rat hippocampal Cornu Ammonis 1 caused by transient brain ischemia/reperfusion (20). SP600125 also markedly improved the survival rate of retinal ganglion cells against acute moderate ocular hypertension (21). In the present study, the administration of SP600125 enhanced the cell viability, and negated some of the effects elicited by sodium formate. Inhibiting JNK activity by SP600125, or similar compounds, may provide a novel and effective strategy to treat methanol intoxication.

The Bax/Bcl-2 ratio in cells regulates the susceptibility of cells to apoptosis (22). The present study confirmed that the expression of Bcl-2 was markedly decreased and the expression of Bax was increased in the $661 \mathrm{~W}$ cells treated with 15 or $30 \mathrm{mM}$ sodium formate. Increased levels of cleaved caspase- 3 and cleaved caspase- 9 in the $661 \mathrm{~W}$ cells treated with sodium formate were also observed. These results suggested that the increases in the $\mathrm{Bax} / \mathrm{Bcl}-2$ ratio and the level of cleaved caspases may be involved in sodium formate-induced, mitochondrion-dependent apoptosis. The pan-caspase inhibitor, Z-VAD-fmk, markedly enhanced the cell viability and circumvented the effect of sodium formate treatment, indicating that apoptosis of the $661 \mathrm{~W}$ cells, induced by sodium formate, occurs via a caspase-dependent pathway.

Autophagy is a cellular pathway responsible for the clearance of proteins and organelles, and therefore a certain degree of autophagy is necessary to maintain normal cellular homeostasis (23). In the present study, the autophagy of lysosomes and an increased expression level of LC3II in the 661W cells was observed, on increasing the exposure of the cells to sodium formate. Ramírez et al (24) demonstrated that hydroquinone damages human retinal Müller cells via the oxidative, mitochondrial and autophagic signaling pathways.

It is possible that cells, which have suffered a mild insult can be rescued through the selective elimination of damaged and proapoptotic mitochondria (those undergoing mitosis), whereas a more profound insult resulting in damage to numerous mitochondria would surpass the capacity for rescue. This would be due to the fact that removal of an excessive number of the mitochondria would leave behind a cell with an insufficient capacity to produce ATP and release cytochrome $c$, and ultimately the apoptosis of the photoreceptor cells would result. Macroautophagy induced by formate may provide an explanation for the decrease in ATP levels. Therefore, formate-induced autophagy may be important in promoting mitochondrial dysfunction, and even apoptosis, in 661W cells. Kunchithapautham and Rohrer (25) demonstrated that apoptotic and autophagic genes may be coexpressed in photoreceptors undergoing degeneration. It was suggested that autophagy is involved in photoreceptor cell death, possibly by initiating apoptosis.
In conclusion, the present study provided evidence that sodium formate induces the apoptosis of $661 \mathrm{~W}$ cells, partly through triggering the JNK pathway. Increased levels of autophagy were observed during the process of cellular damage caused to the $661 \mathrm{~W}$ cells by treatment with sodium formate. Autophagy has been postulated to be involved in the pathogenesis of numerous retinal diseases, including age-associated macular degeneration and diabetic retinopathy. Therefore, studies of formate-induced $661 \mathrm{~W}$ cell dysfunction may provide valuable insights into the pathogenesis of these retinal diseases.

\section{Acknowledgements}

The present study was supported by the Bethune Youth Fund of Jilin University (no. 2013206043).

\section{References}

1. Massoumi G, Saberi K, Eizadi-Mood N, Shamsi M, Alavi M and Morteza A: Methanol poisoning in Iran, from 2000 to 2009. Drug Chem Toxicol 35: 330-333, 2012.

2. Harris C, Dixon M and Hansen JM: Glutathione depletion modulates methanol, formaldehyde and formate toxicity in cultured rat conceptuses. Cell Biol Toxicol 20: 133-145, 2004.

3. Harris C, Wang SW, Lauchu JJ and Hansen JM: Methanol metabolism and embryotoxicity in rat and mouse conceptuses: Comparisons of alcohol dehydrogenase (ADH1), formaldehyde dehydrogenase (ADH3), and catalase. Reprod Toxicol 17: 349-357, 2003.

4. Seme MT, Summerfelt P, Neitz J, Eells JT and Henry MM: Differential recovery of retinal function after mitochondrial inhibition by methanol intoxication. Invest Ophthalmol Vis Sci 42: 834-841, 2001.

5. Seme MT, Summerfelt P, Henry MM, Neitz J and Eells JT: Formate-induced inhibition of photoreceptor function in methanol intoxication. J Pharmacol Exp Ther 289: 361-370, 1999.

6. Eells JT, Salzman MM, Lewandowski MF and Murray TG: Formate-induced alterations in retinal function in methanol-intoxicated rats. Toxicol Appl Pharmacol 140: 58-69, 1996.

7. Treichel JL, Henry MM, Skumatz CM, Eells JT and Burke JM: Formate, the toxic metabolite of methanol, in cultured ocular cells. Neurotoxicology 24: 825-834, 2003.

8. Eells JT, Henry MM, Summerfelt P, Wong-Riley MT, Buchmann EV, Kane M, Whelan NT and Whelan HT: Therapeutic photobiomodulation for methanol-induced retinal toxicity. Proc Natl Acad Sci USA 100: 3439-3444, 2003.

9. Kubáň P, Foret F and Bocek R: Capillary electrophoresis with contactless conductometric detection for rapid screening of formate in blood serum after methanol intoxication. J Chromatogr A 1281: 142-147, 2013.

10. Sundaresan M, Yu ZX, Ferrans VJ, Irani K and Finkel T: Requirement for generation of $\mathrm{H} 2 \mathrm{O} 2$ for platelet-derived growth factor signal transduction. Science 270: 296-299, 1995.

11. Zhang Y, Zhou L, Bao YL, Wu Y, Yu CL, Huang YX, Sun Y, Zheng LH and Li YX: Butyrate induces cell apoptosis through activation of JNK MAP kinase pathway in human colon cancer RKO cells. Chem Biol Interact 185: 174-181, 2010.

12. Los M, Wesselborg S and Schulze-Osthoff K: The role of caspases in development, immunity, and apoptotic signal transduction: Lessons from knockout mice. Immunity 10: 629-639, 1999.

13. Barceloux DG, Bond GR, Krenzelok EP, Cooper H and Vale JA; American Academy of Clinical Toxicology Ad Hoc Committee on the Treatment Guidelines for Methanol Poisoning: American Academy of Clinical Toxicology practice guidelines on the treatment of methanol poisoning. J Toxicol Clin Toxicol 40: 415-446, 2002.

14. Chen JM, Zhu GY, Xia WT and Zhao ZQ: Proteomic analysis of rat retina after methanol intoxication. Toxicology 293: 89-96, 2012.

15. Saoudi M, Ben Hsouna A, Trigui M, Jamoussi K, Jaoua S and El Feki A: Differential oxidative stress responses to methanol in intraperitoneally exposed rats: Ameliorative effects of Opuntia vulgaris fruit extract. Toxicol Ind Health 28: 549-559, 2012. 
16. Nakano H, Nakajima A, Sakon-Komazawa S, Piao JH, Xue X and Okumura K: Reactive oxygen species mediate crosstalk between NF-kappaB and JNK. Cell Death Differ 13: 730-737, 2006.

17. Lorin S, Pierron G, Ryan KM, Codogno P and Djavaheri-Mergny M: Evidence for the interplay between JNK and p53-DRAM signalling pathways in the regulation of autophagy. Autophagy 6: 153-154, 2010.

18. Zhang Y and Chen F: Reactive oxygen species (ROS), troublemakers between nuclear factor-kappaB (NF-kappaB) and c-Jun NH(2)-terminal kinase (JNK). Cancer Res 64: 1902-1905, 2004.

19. Green DR and Reed JC: Mitochondria and apoptosis. Science 281: 1309-1312, 1998.

20. Niu YL, Li C and Zhang GY: Blocking Daxx trafficking attenuates neuronal cell death following ischemia/reperfusion in rat hippocampus CA1 region. Arch Biochem Biophys 515: 89-98, 2011.
21. Sun H, Wang Y, Pang IH, Shen J, Tang X, Li Y, Liu C and Li B: Protective effect of a JNK inhibitor against retinal ganglion cell loss induced by acute moderate ocular hypertension. Mol Vis 17: 864-875, 2011.

22. Vander Heiden MG and Thompson $\mathrm{CB}$ : $\mathrm{Bcl}-2$ proteins: Regulators of apoptosis or of mitochondrial homeostasis? Nat Cell Biol 1: E209-216, 1999.

23. García-Escudero V and Gargini R: Autophagy induction as an efficient strategy to eradicate tumors. Autophagy 4: 923-925, 2008.

24. Ramírez C, Pham K, Franco MF, Chwa M, Limb A, Kuppermann BD and Kenney MC: Hydroquinone induces oxidative and mitochondrial damage to human retinal Muller cells (MIO-M1). Neurotoxicology 39: 102-108, 2013.

25. Kunchithapautham K and Rohrer B: Apoptosis and autophagy in photoreceptors exposed to oxidative stress. Autophagy 3: 433-441, 2007. 